\title{
Comparison of process behavior, microstructure and mechanical properties of ultrasound enhanced friction stir welded titanium/ titanium joints
}

\author{
Marco Thomae $^{1} \cdot$ Andreas Gester $^{1} \cdot$ Guntram Wagner $^{1}$
}

Received: 8 October 2021 / Accepted: 16 February 2022 / Published online: 28 February 2022

(c) The Author(s) 2022

\begin{abstract}
Titanium as a high-performance material offers great potential for a wide range of applications with different aspects like lightweight-constructions, biocompatibility as well as design and is used in various industrial areas like the transportation sector or in medical and sports engineering. To exploit the full potential of titanium, there is still a need for innovative and efficient joining techniques compared to conventional methods. The process of friction stir welding as a solid-state joining method is able to produce high-quality similar joints of titanium. Nevertheless, there are still some challenging aspects when friction stir welding titanium like the formation of oxide layers that affect the mechanical properties especially in the field of fatigue negatively. The superposition of power ultrasound on the friction stir welding process can address this issue. Therefore, the hybrid process of ultrasound enhanced friction stir welding was applied on similar Ti6Al4V/Ti6Al4V joints in a butt joint configuration to reduce the amount of oxide layers and improve the fatigue lifetime of the joints. For the joint configuration, a positive impact of the power ultrasound could be identified by the breakup of oxide layers and an increase in the tensile strength of $16 \%$. Also stepwise load increase tests revealed a higher estimated fatigue strength for ultrasound enhanced friction stir welded specimen in this butt joint configuration.
\end{abstract}

Keywords Ultrasound enhanced friction stir welding $\cdot$ Titanium $\cdot$ Similar joints $\cdot$ Tensile strength $\cdot$ Fatigue

\section{Introduction}

Global society's demand for increasing mobility is countered by continuously rising energy costs. Lightweight construction addresses these demands, since a reduction in transportation vehicle mass is directly accompanied by a reduction in energy consumption [1]. As the aerospace, automotive, marine and rail vehicle industries increasingly exhaust aerodynamic and design options in respect to weight reduction, the use

Recommended for publication by Commission III-Resistance Welding, Solid State Welding, and Allied Joining Process

Marco Thomae

marco.thomae@mb.tu-chemnitz.de

Andreas Gester

andreas.gester@mb.tu-chemnitz.de

Guntram Wagner

guntram.wagner@mb.tu-chemnitz.de

1 Chair of Composites and Material Compounds, Chemnitz University of Technology, Chemnitz, Germany of high-performance light metals such as titanium alloys is becoming increasingly important due to their outstanding specific strength and corrosion resistance. Therewith, Ti6Al4V is the most important titanium material in the industry, accounting for over $50 \%$ of annual world production [2]. The realization of components made of titanium alloys places special demands on the joining processes. Due to the high affinity of titanium to the air gases nitrogen, hydrogen and oxygen at temperatures above $300^{\circ} \mathrm{C}$, high-quality titanium welded joints can so far only be realized by methods using inert gas like the industrially established tungsten inert gas welding (TIG) process or the laser welding process [2, 3]. Beside another possibility of joining titanium by riveting, all of these methods provide some disadvantages like high energy consumption, comparatively low welding speeds, need for filler material or overlap configuration and therewith additional weight. Friction stir welding (FSW), developed at the Welding Institute (TWI) in 1991, is an innovative and efficient alternative [4]. As a solid-state joining process, it is characterized by a process temperature of about $80 \%$ of the melting temperature of the joining partners [5]. Previous investigations in the field 
of friction stir welding of similar Ti/Ti joints showed the existence of different microstructures or microstructural fractions (bimodal or lamellar), depending on the selected FSW parameters or tools and the resulting process temperatures in the range below or above the beta-transus temperature range (about $800^{\circ} \mathrm{C}-995^{\circ} \mathrm{C}$ ) of this titanium alloy and resulting cooling rates [6-10]. Furthermore, comparatively strong wear phenomena were also found on the FSW tools used [11]. Additional investigations on friction stir welding of similar Ti6Al4V/Ti6Al4V joints often proved the presence of oxide layers in the joining zone [7, 9]. Despite these oxide layers, high quasi-static bond strengths could be achieved, whereas the oxides proved to be extremely detrimental to the achievable fatigue lifetimes in the area of cyclic loading [12]. With respect to an improved stirring as well as a reduction of oxide layers for similar joints, hybrid joining processes such as ultrasound enhanced friction stir welding (USE-FSW) have been developed [13, 14]. The USE-FSW process is characterized by the time-synchronous and parallel coupling of high-frequency power ultrasound into a joining partner, whereby two mechanisms of action come into play. On the one hand, the power ultrasound interacts with discontinuities and, under certain conditions, has the ability to reduce or destroy such artifacts. This effect is applied in medical technology for the removal of kidney stones [15]. On the other hand, the occurrence of the acousto-plastic effect can reduce the yield stress of the joining partners [16]. The combination of these two mechanisms of action results in numerous advantages, including the plasticization of a larger volume of material, more homogeneous stirring of the joining zone, better through-welding and the reduction or avoidance of intermetallic phases (dissimilar composites) and oxide layers (similar composites) [17-21]. So far, there is no literature on the application of power ultrasound enhanced friction stir welding on similar titanium/titanium joints and subsequent investigations on the process behavior as well as microstructural and mechanical properties.

To close this gap in knowledge, the aim of the presented investigation is the identification of the effects of the superimposed power ultrasound during the friction stir welding process of similar Ti6Al4V/Ti6Al4V joints in a butt joint configuration with a comparatively short joint length of only $100 \mathrm{~mm}$ simulating possible unstable welding conditions via thermal analysis, microstructural investigations and destructive mechanical testing.

\section{Experimental procedure}

For the base material, the industrial commonly used $\alpha-\beta$-titanium alloy Ti6A14V with sheet dimensions of $140 \mathrm{~mm} \times 100 \mathrm{~mm} \times 1.25 \mathrm{~mm}$ was used. The chemical composition is shown in $1^{*}$ MERGEFORMAT Table 1 according to the datasheets provided by the manufacturer. The surfaces of the sheets were treated with acetone to remove contaminations before performing the weldings.

The FSW and USE-FSW butt joints had a length of $100 \mathrm{~mm}$. This comparatively short joint length was chosen intentionally with the aim to investigate the influence of power ultrasound on the welding process, the resulting joints and their properties for possible unstable welding conditions compared to conventional FSW. These weldings were performed on a modified 4-axis CNC machining center DMG Mori DMU80T. Therewith, force-controlled welding was ensured by the use of four Kistler load cells, which were fixed under the machine bench and performing an in process target-performance comparison of the vertical force. The tools used were based of tungsten with a reinforcement of $1 \%$ lanthanum oxides. It had a shoulder diameter of $11 \mathrm{~mm}$, a probe length of $1.15 \mathrm{~mm}$ and a conic shape of the probe (diameter change from 8 to $4 \mathrm{~mm}$ ). For the welding of titanium, a special tool holder was required, that ensured a cooling of the spindle as well as an inert gas shielding of the weld zone (Fig. 1).

To realize friction stir welding with additional ultrasound enhancement, the machine also has been equipped with a Schunk Sonosystems roll seam module RM20. This module works with a resonance frequency of $20 \mathrm{kHz}$ and a maximum amplitude of $38 \mu \mathrm{m}$ whereas for the investigations an amplitude of $18 \mu \mathrm{m}$ (corresponding to $20 \%$ of the maximum amplitude) was chosen. Using this comparatively low ultrasound amplitude, an overheating of the sonotrode at the transmission area could be avoided. Both amplitude values were determined via laser vibrometry of the free oscillating non-coupled sonotrode. Through an integrated LabVIEW control unit, the roll seam module runs parallel and synchronously to the tool with a constant distance of $95 \mathrm{~mm}$ apart from the faying surfaces. This constant distance between the ultrasound transmission area and the weld zone corresponds in good approximation to a quarter of an ultrasound wavelength $(\lambda / 4)$ for a longitudinal oscillation in titanium and is based on construction constraints as well as a former design
Table 1 Chemical composition of the titanium alloy Ti6Al4V

\begin{tabular}{lllllllll}
\hline Alloy & \multicolumn{1}{l}{ Elements $(\mathrm{wt} \%)$} & & & & & \\
\hline Ti6Al4V & $\mathrm{Al}$ & $\mathrm{V}$ & $\mathrm{Fe}$ & $\mathrm{C}$ & $\mathrm{N}$ & $\mathrm{O}$ & $\mathrm{H}$ & $\mathrm{Ti}$ \\
& $5.5-6.75$ & $3.5-4.5$ & 0.4 & 0.08 & 0.05 & 0.2 & 0.015 & $\mathrm{Bal}$ \\
\hline
\end{tabular}


for a maximum longitudinal oscillation [14]. Figure 2 shows the operating principle of this USE-FSW process.

In a first step, best possible process parameters for FSW were identified via design of experiments (DOE) in the form of the central composite design method (CCD) with a maximum tensile strength as the target. This experimental design has been accomplished position controlled and the resulting best possible process parameters were applied to force-controlled FSW as well as USE-FSW to compare and identify the influence of the power ultrasound transmission. The advancing side was chosen for the power ultrasound transmission and a pulse/pause ratio of $2 / 3 \mathrm{~s}$ pulse to $1 / 3 \mathrm{~s}$ pause was applied in addition to the comparatively low ultrasound amplitude, to avoid an overheating of the sonotrode. I* $^{*}$ MERGEFORMAT Table 2 shows the FSW and ultrasound parameters for the USE-FSW.

Furthermore, the process temperature was recorded thermographically by an Optris infrared pyrometer, which was fixed at the spindle holder under an angle of $20^{\circ}$ toward the horizontal and leading the tool with a constant working distance of $62.5 \mathrm{~mm}$ over the complete welding processes (Fig. 1). Therewith, the temperature

Fig. 1 Used tool holder

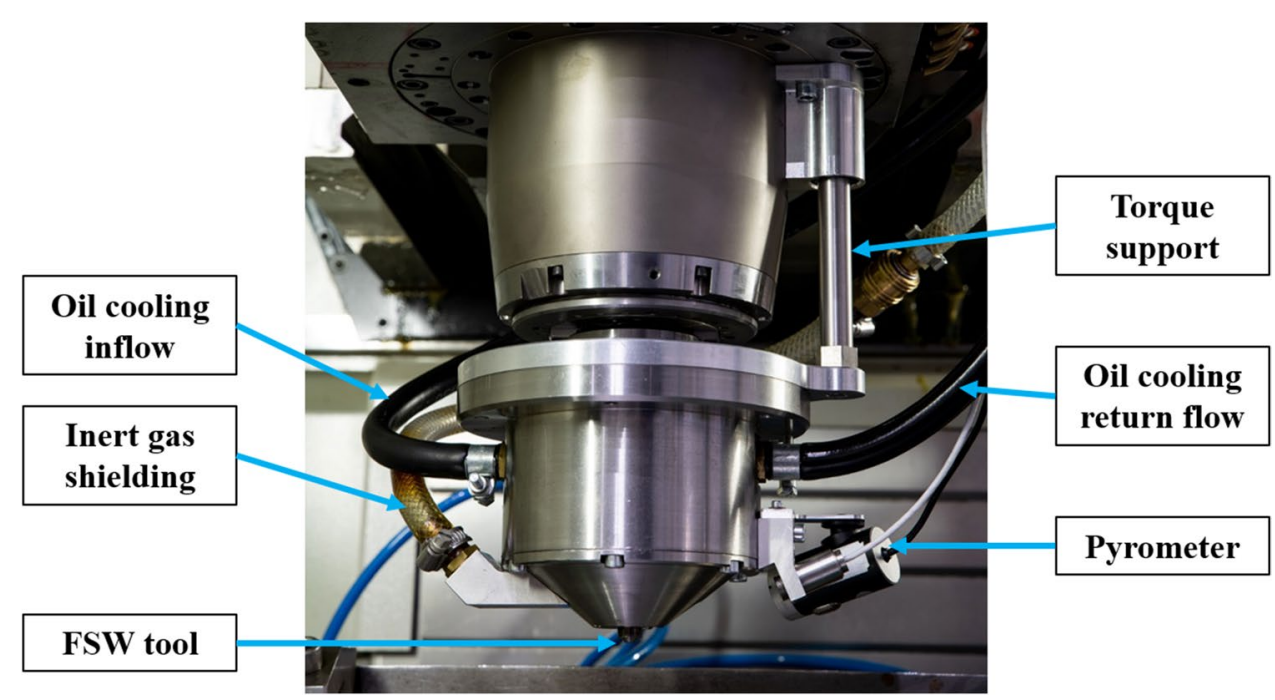

Fig. 2 Principle of ultrasound enhanced friction stir welding

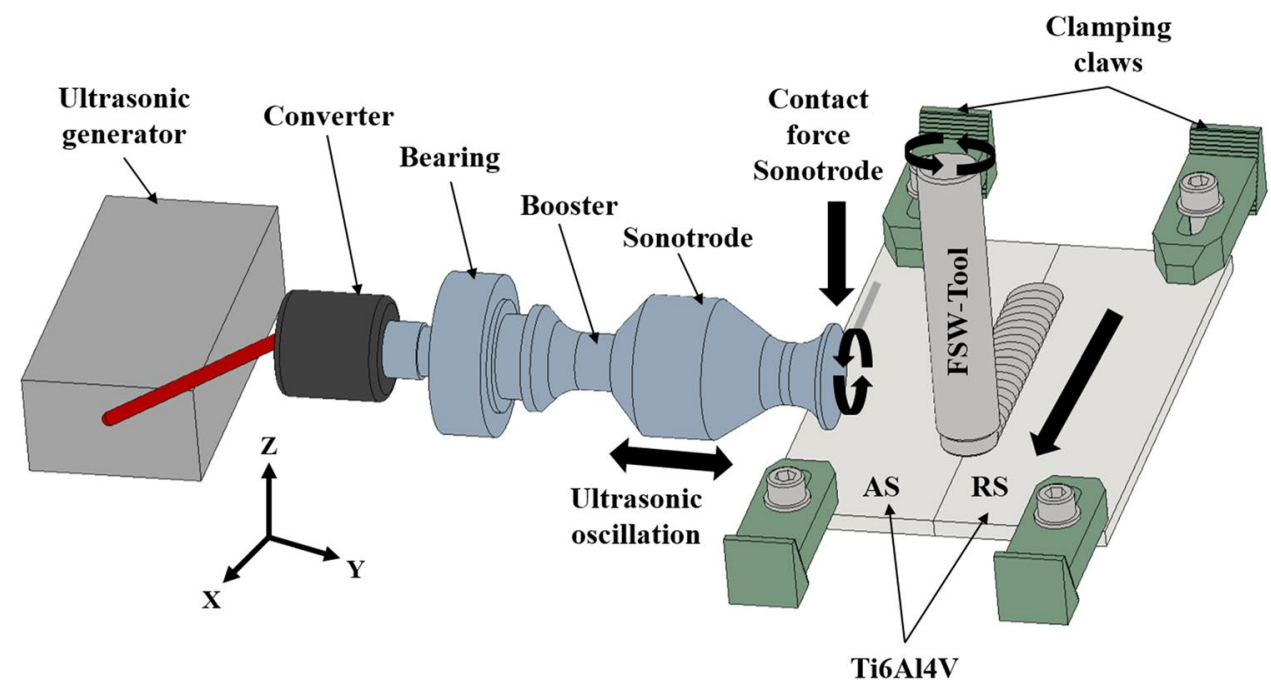

Ti6Al4V
Table 2 FSW and ultrasound parameters for the USE-FSW

\begin{tabular}{llllll}
\hline FSW & Rotational speed & Tilt angle & Dwell time & Feed & Axial force \\
& $1000 \mathrm{rpm}$ & $2^{\circ}$ & $5 \mathrm{~s}$ & $75 \mathrm{~mm} / \mathrm{min}$ & $4 \mathrm{kN}$ \\
USE-FSW & Ultrasound frequency & Amplitude & Pulse/pause ratio & Contact force & Ultrasound power \\
& $20 \mathrm{kHz}$ & $18 \mu \mathrm{m}$ & $2 / 3 \mathrm{~s}$ pulse $/ 1 / 3 \mathrm{~s}$ pause & $1.5 \mathrm{kN}$ & $228 \mathrm{~W}$ \\
\hline
\end{tabular}


at the contact area between FSW tool and the surface of the sheets could be detected. The temperature field of the pyrometer ranged from $385^{\circ} \mathrm{C}$ to $1600^{\circ} \mathrm{C}$, and its emissivity was chosen for titanium with $0.6(1.6 \mu \mathrm{m}$ spectral sensitivity) whereas the surface of the titanium sheets was blank. For examining cross sections of the resulting joints via light microscopy, the joints were cut and embedded in embedding resin and ground with $\mathrm{SiC}$ paper. Afterwards, they were polished and cleaned with ethanol. Light microscopic investigations were carried out on an Olympus GX51 and scanning electron microscopy on a ZEISS LEO1455VP. The preparation of the joints for tensile testing took place by water jet cutting into samples according to shape E of DIN 50,125. The tensile tests were performed on a Zwick Roell tensile testing machine with a strain rate of $2.5 \times 10^{-4}$ at room temperature. For each joint, three specimens were taken with distances from the starting point of the joint of $21.90 \mathrm{~mm}, 44.30 \mathrm{~mm}$ and $66.70 \mathrm{~mm}$ (Fig. 3). The determination of the fatigue limit took place by using a servo-hydraulic testing machine MTS Landmark $100 \mathrm{kN}$. The fatigue tests were performed force-controlled at room temperature with a stress ratio of $\mathrm{R}=0.1$ and a frequency of $5 \mathrm{~Hz}$. For the determination of the elongation of the specimens, a clip gage was used. The fatigue specimens were also manufactured by water jet cutting and subsequently polished to a roughness of $\mathrm{R}_{\mathrm{a}}=0.2 \mu \mathrm{m}$. The geometry of the specimens was designed following DIN 50,100, and four specimen were taken per joint with distances from the starting point of the joint of $19.50 \mathrm{~mm}, 35.50 \mathrm{~mm}, 51.50 \mathrm{~mm}$ and $67.50 \mathrm{~mm}$ (Fig. 3) [22]. These fatigue investigations were divided in stepwise load increase tests (LIT) and constant amplitude tests (CAT). Following the PHYBAL according to the work of
Ebel-Wolf principle, the LIT were used for an accelerated estimation of the approximated fatigue strength [23], that should be verified afterwards by a small number of CAT following the staircase method of DIN 50,100 with a fatigue limit of $2 \times 10^{6}$ cycles [22]. The number of tested specimens for each condition was three for the LIT and five (FSW) or rather seven (USE-FSW) for the CAT. According to the literature of the PHYBAL principle, the LIT had a number of 10.000 cycles for each step before increasing the load by $17 \mathrm{MPa}$ per step [23]. A suitable initial stress amplitude of $88 \mathrm{MPa}$ was chosen based on the results of the tensile testing. The materials measurand for the estimated fatigue lifetime of $2 \times 10^{6}$ cycles was the maximum plastic strain $\left(\varepsilon_{\mathrm{pl}, \max }\right)$, that was calculated by subtraction of the maximum elastic strain ( $\varepsilon_{\mathrm{el}, \mathrm{max}}$; also calculated from the Young's modulus and the time-dependent present stress) from the measured maximum total strain $\left(\varepsilon_{\text {to,max }} ;\right.$ measured by the clip gage). The LIT were run until the specimens failed. Afterwards, the development of the maximum plastic strain was investigated and if a rise occurred this number of cycles and the belonging stress level was assumed to be the estimated fatigue strength. Whenever no explicit reaction for the maximum plastic strain curve could be detected, a third-degree polynomial $\left(\varepsilon_{\mathrm{pl} \text {,math }}\right)$ was used to fit the values of the plastic strain to a mathematical function according to the PHYBAL principle [23]. Afterwards, the first derivative of this function $\left(\varepsilon_{\mathrm{pl} \text {,math }}\right)$, which represented the rise of the function, was calculated and used to place tangents at its minimum (linear rise) and maximum (exponential rise), who intersect at a certain point. The number of cycles and the corresponding stress amplitude of this intersection point of the two tangents then was presumed as the estimated fatigue limit.
Fig. 3 Cut out positions of the specimen for tensile and fatigue testing
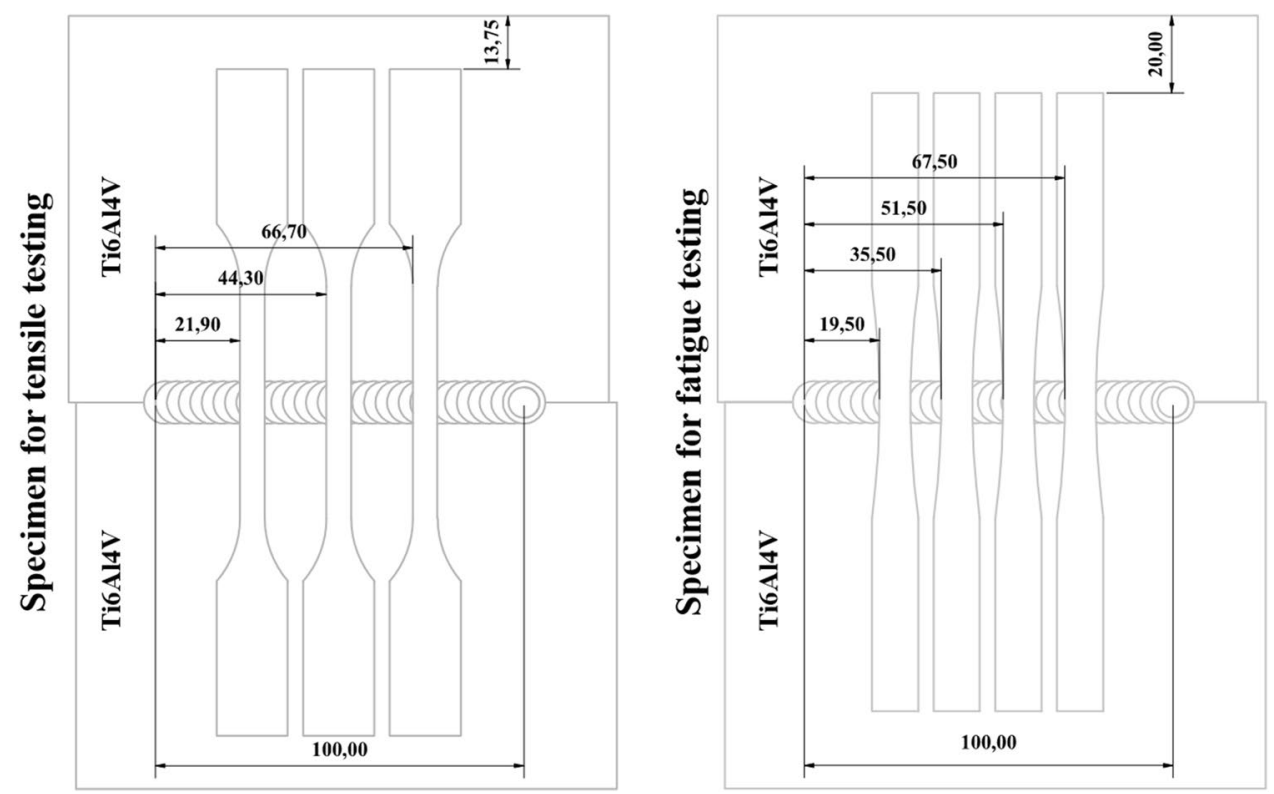
The step height of the stress level for the subsequent staircase method on the CAT was chosen to isolate the fatigue strength in a short term.

\section{Results and discussion}

Similar Ti6Al4V/Ti6Al4V joints could be realized by using the FSW as well as the USE-FSW process and will be comparatively analyzed hereinafter.

\subsection{Process Behavior}

The thermal behavior for the FSW (dark blue line) and USEFSW (bright blue line) processes is shown in Fig. 4 in the form of comparative plots of the thermographic temperature development.

The temperature curve of the FSW process (dark blue line) reaches higher temperature values with an average temperature of about $950^{\circ} \mathrm{C}$ and runs more homogenously than the USE-FSW process (bright blue line), which shows an average temperature of about $915^{\circ} \mathrm{C}$. This lower process temperature development for the USE-FSW could be

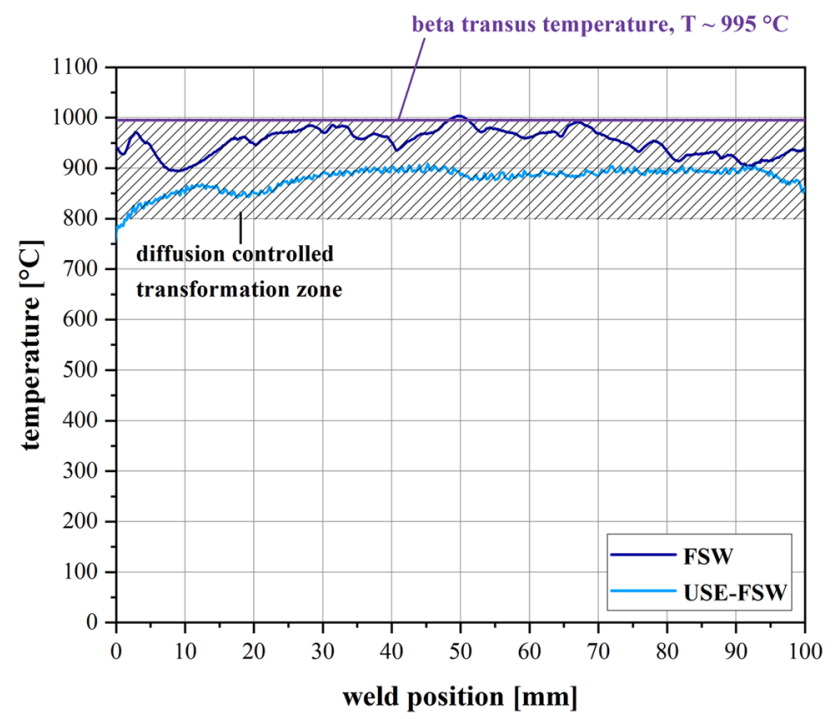

Fig. 4 Comparison of the thermographic temperature development for FSW and USE-FSW attributed to the acousto-plastic effect, which could have caused a softening of the titanium and therewith a change in the friction conditions and is in accordance with the literature [24]. Regarding the development of the curves, the ultrasound enhancement seems to lead to a more homogenous and stable temperature distribution and therewith a more stable welding process for this short joint length. In contrast to that, the conventional FSW process seems to need a longer time to reach a stable condition, which is typical for friction stir welding as mentioned by Zhai et al. and Wu et. al. [25, 26]. Furthermore, both curves are located in the diffusion-controlled transformation zone for Ti6Al4V extending from $800^{\circ} \mathrm{C}-995^{\circ} \mathrm{C}$ (striped area), what leads to the assumption that lamellar $\alpha$ - and $\beta$-titan will be present in the resulting microstructure for both joints with varying volume content.

\subsection{Microstructure}

Regarding the assumption proposed before, subsequent microstructural analysis was carried out. Figure 5 shows the light microscopic cross-section images of the FSW and USE-FSW joint.

Compared to the USE-FSW joint, the conventional FSW joint seems to exhibit remaining oxide layers on the retreating side as well as in the root region of the joint (see red dashed ellipses). This finding is in accordance with the literature on ultrasonic-assisted friction stir welding, that mentioned the reduction of such brittle oxide layers due to the interaction of the power ultrasound with these structures and the resulting break-up of them leading to enhanced mechanical properties [7, 19]. Apart from that, the geometric characteristics of the joining zone are almost identical, with the characteristic areas of the stirring zone (SZ), the thermomechanically affected zone (TMAZ), the heat-affected zone (HAZ) and the base material (BM) being clearly visible in the light microscopic images.

To gain more detailed information about the resulting microstructure of the joints, scanning electron microscopy was conducted for the different areas of the welding zones of the FSW and USE-FSW joints (Fig. 6).

The base material (BM) for both joints is characterized by a primary globular $\alpha 1$ titanium structure with $\beta 1$ titanium located at the grain boundaries, which is characteristic
Fig. 5 Cross-section images of Ti6Al4V/Ti6Al4V FSW and USE-FSW joints

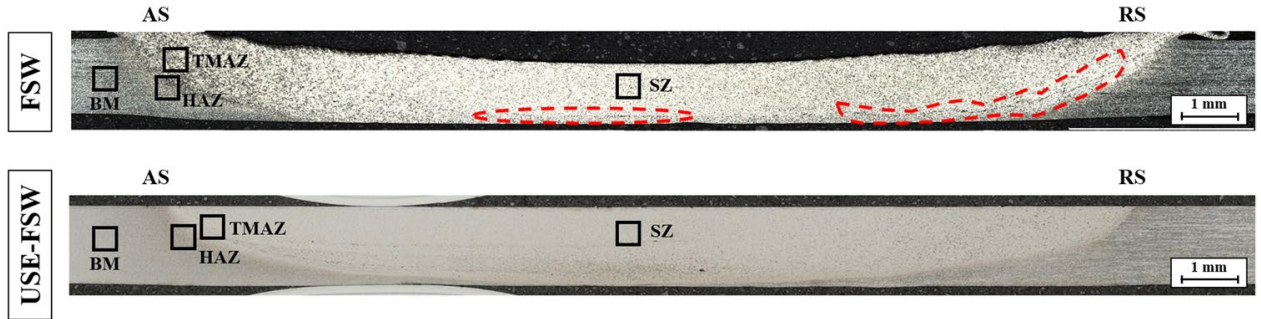


Fig. 6 Scanning electron microscopic images of Ti6Al4V/ Ti6Al4V FSW and USE-FSW joints

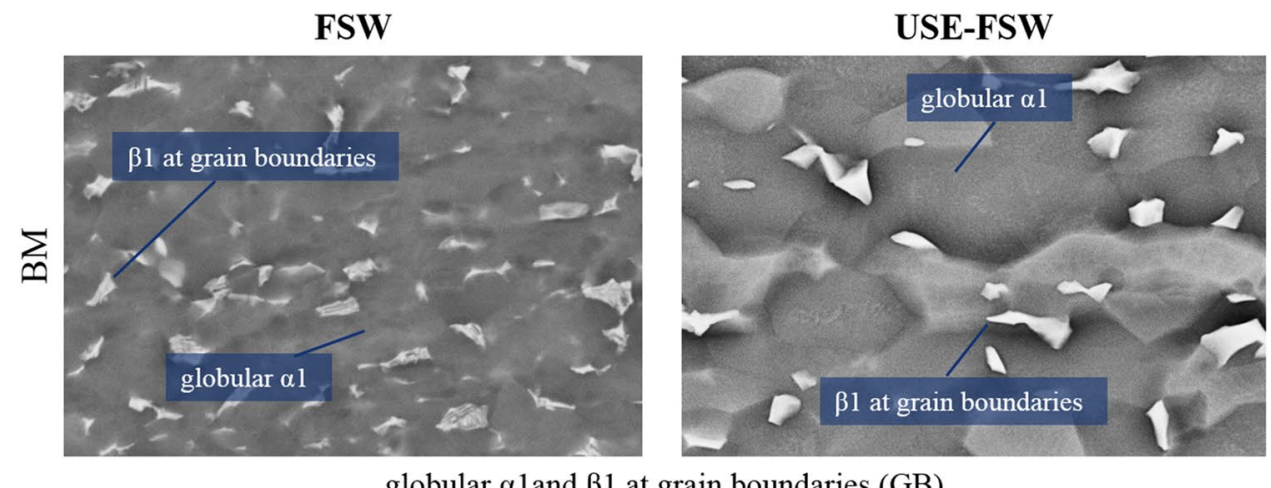

globular $\alpha$ land $\beta 1$ at grain boundaries (GB)
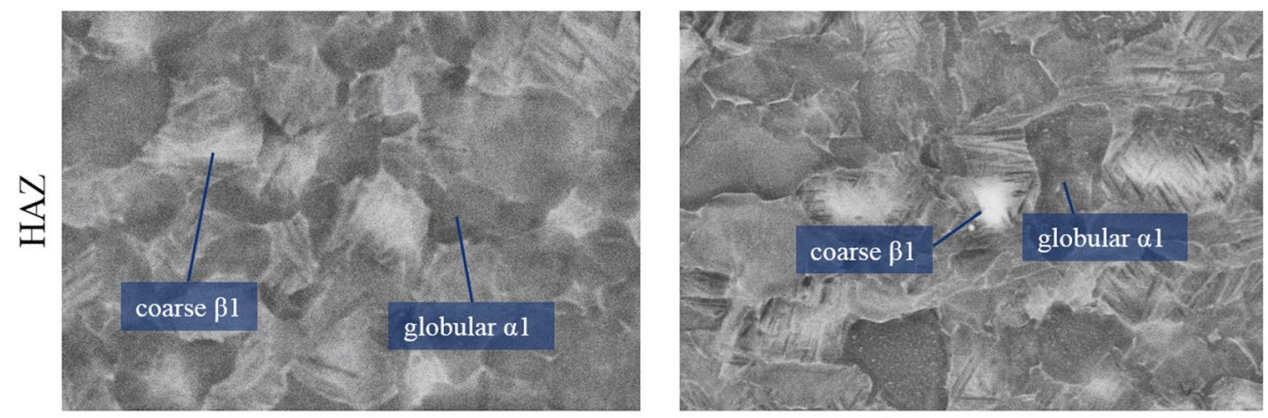

globular $\alpha 1$, coarsened $\beta 1$, $\mathrm{T}<$ beta transus
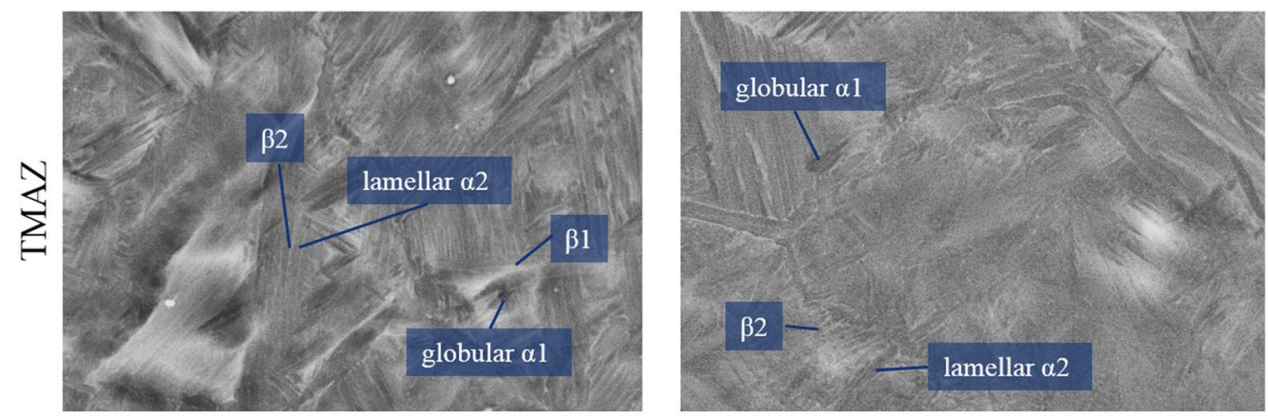

$\beta 1$ at GB of fined $\alpha 1$, growth of lamellar $\alpha 2$ in $\beta 2$ $\mathrm{T} \sim$ beta transus
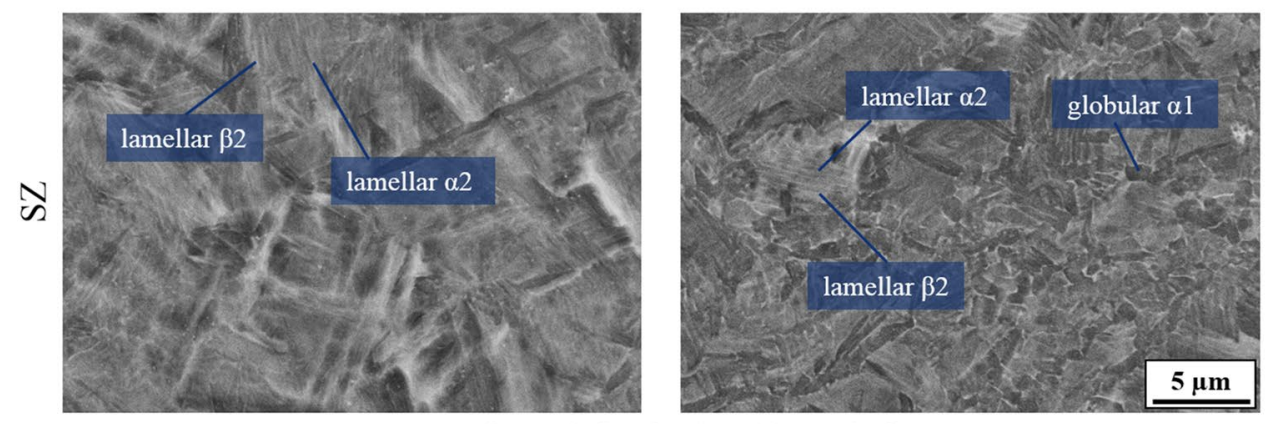

Transformed, fine $\beta 2$, lamellar $\alpha 2$ in $\beta 2$ $\mathrm{T}>$ beta transus only for FSW

for Ti6Al4V. In the subsequent heat-affected zone (HAZ), both the FSW and USE-FSW joints still exhibit the primary globular $\alpha 1$ titanium microstructure, with the $\beta 1$ titanium coarsened by the process-induced temperature increase in the HAZ. As expected, since lamellar $\alpha 2+\beta 2$-titanium is not yet present in this area, the heat-affected zone did not reach the diffusion controlled transformation zone beginning at $800{ }^{\circ} \mathrm{C}$. In comparison, the adjoining areas of the 
thermo-mechanically affected zones (TMAZ) of the two joints already show portions of secondary lamellar $\alpha 2+\beta 2$ titanium structure in addition to remaining primary $\alpha 1$ titanium and thus possess a bimodal microstructure. For the transverse section of the joint with ultrasound enhancement, no primary $\beta 1$-titanium could be found. Therefore, it can be concluded that the TMAZ of the FSW as well as the USE-FSW joint experienced temperatures in the range of $800^{\circ} \mathrm{C}$ to $995^{\circ} \mathrm{C}$ during the joining processes. Accordingly, the presence of a lamellar $\alpha 2+\beta 2$ titanium structure was expected for the stirred zone (SZ). The SZ of the FSW joint showed an exclusively lamellar microstructure, whereas the USE-FSW joint also exhibited sporadic primary globular $\alpha 1$ titanium in its stirred zone. These minor differences regarding the microstructural characteristics can be explained by the previously detected process temperatures, which were higher for the FSW joint and thus, with regard to the thermographic measurement methodology, may well have been consistently above $995{ }^{\circ} \mathrm{C}$. In general, the resulting microstructures are in accordance with the literature and it appears that the ultrasound enhancement only had an indirect influence on the microstructure due to its believed impact on the process temperatures [6-10].

\subsection{Mechanical characterization-Quasi-static properties}

Additionally quasi-static tensile testing has been carried out in order to analyze the correlation between the microstructure and the tensile properties of the FSW and USEFSW joints. Figure 7 depicts the achieved ultimate tensile strengths of the base material, the FSW and USE-FSW joints.

For the ultimate tensile strength of the Ti6Al4V BM, a characteristic value of $1007 \mathrm{MPa}$ could be attained, whereas the FSW joint showed a decrease of about $13 \%$ (877 MPa) $[6,7,27,28]$. The USE-FSW joint, on the other hand, is on the same level as the base material regarding its ultimate tensile strength of $1017 \mathrm{MPa}$. The reason for this increased ultimate tensile strength may be the possibly detected reduction of oxide layers and the better intermixing of the titanium sheets due to the additional power ultrasound, what is in accordance with the literature [17-20]. Furthermore, the presence of portions of the primary globular $\alpha 1$ titanium in the stirred zone of the USE-FSW composite may also have led to a more homogeneous transition in the microstructure, as evidenced by the greater strain hardening capacity of the globular $\alpha 1$ titanium in the work of Ahmadian et al. [29].

\subsection{Mechanical characterization-cyclic properties}

Based on the findings regarding the quasi-static mechanical properties, further investigations on the cyclic properties

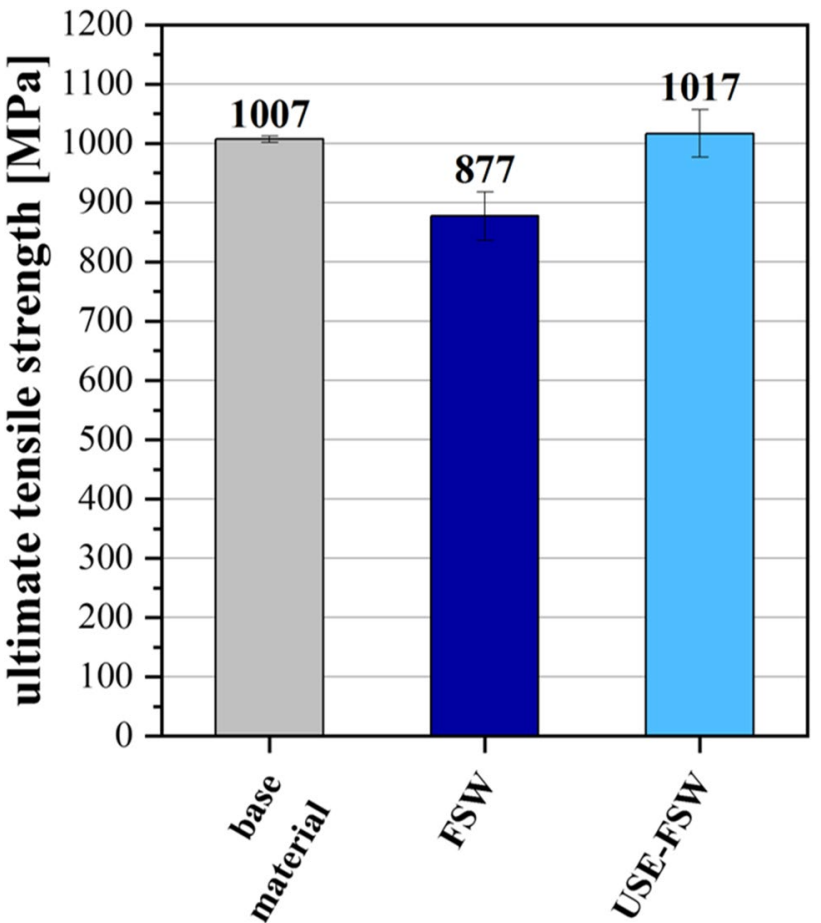

Fig. 7 Comparison of the ultimate tensile strength of Ti6Al4V/ Ti6Al4V FSW and USE-FSW joints

were carried out by fatigue testing of the FSW and USEFSW joints. To avoid time-consuming and material-intensive Wöhler curves, stepwise load increase tests were performed first (Fig. 8).

From the representative stepwise load increase test curves, it becomes evident that a higher estimated fatigue strength amplitude of about $210 \mathrm{MPa}$ was obtained for the USE-FSW specimens compared to about $175 \mathrm{MPa}$ for the FSW specimens. This increase of about $20 \%$ corresponded to the findings from the investigations so far and could be explained with the impact of the additional power ultrasound on the process temperature, the microstructure and the ultimate tensile strengths. Based on these results, constant amplitude tests were performed following the staircase method using the estimated fatigue strength amplitude as initial loads.I* MERGEFORMAT Fig. 9 shows the determined stress amplitude-dependent lifetimes of the FSW and USEFSW fatigue specimens as well as their fracture locations.

Unlike the load increase tests, the results of the constant amplitude tests did surprisingly not prove a higher fatigue strength amplitude for the USE-FSW condition that passed the fatigue limit of $2 \times 10^{6}$ load cycles $\left(\mathrm{N}_{\text {pass }}\right)$ for $123.75 \mathrm{MPa}$ as well as $135 \mathrm{MPa}$. The FSW condition achieved the same maximum fatigue strength of $135 \mathrm{MPa}$. Furthermore, regarding the area of the high cycle fatigue below the fatigue limit the FSW process seemed to be beneficial. The fact that the fatigue behavior determined via constant amplitude tests 
Fig. 8 Comparison of the stepwise load increase tests of Ti6Al4V/Ti6Al4V FSW and USE-FSW joints
Fig. 9 Comparison of the constant amplitude tests of Ti6Al4V/Ti6Al4V FSW and USE-FSW joints
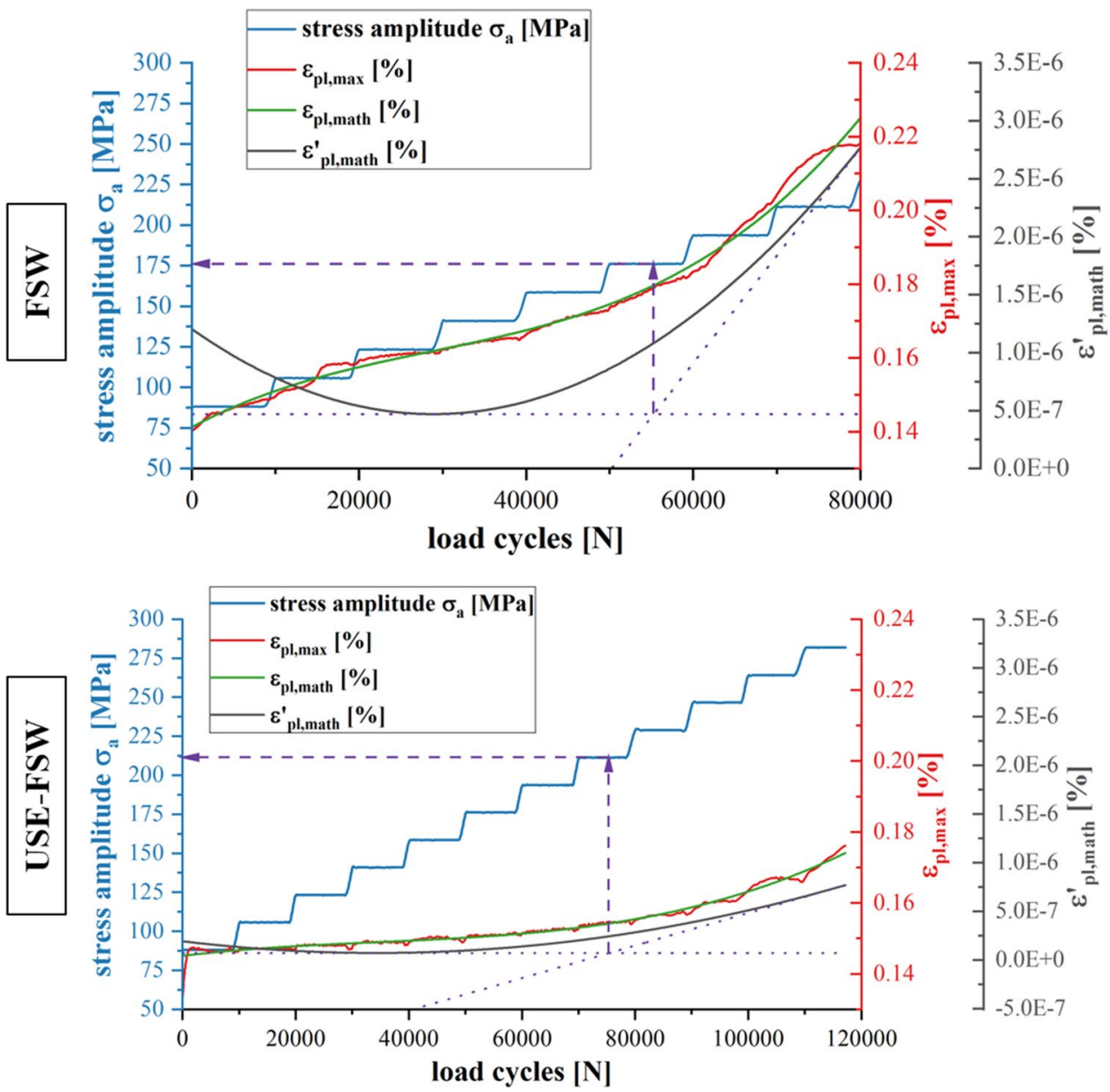

\begin{tabular}{|c|c|c|}
\hline \multicolumn{3}{|c|}{ FSW } \\
\hline$\sigma_{\mathrm{a}}$ & $\mathbf{N}$ & $\begin{array}{l}\text { fracture } \\
\text { location }\end{array}$ \\
\hline 193.5 & 15500 & HAZ \\
\hline 180 & 248270 & SZ \\
\hline 157.5 & 159780 & $\mathrm{BM}$ \\
\hline 157.5 & 830090 & $\mathrm{SZ}$ \\
\hline 135 & $2000000\left(N_{\text {pass }}\right)$ & - \\
\hline
\end{tabular}

\begin{tabular}{|l|l|l|}
\hline \multicolumn{3}{|c|}{$\boldsymbol{| c |}$ USE-FSW } \\
\hline \multicolumn{1}{|c|}{$\boldsymbol{\sigma}_{\mathbf{a}}$} & \multicolumn{1}{c|}{$\mathbf{N}$} & $\begin{array}{l}\text { fracture } \\
\text { location }\end{array}$ \\
\hline 146.25 & 193571 & $\mathrm{SZ}$ \\
\hline 146.25 & 150607 & $\mathrm{HAZ}$ \\
\hline 140.625 & 21267 & $\mathrm{SZ}$ \\
\hline 135 & $2000000\left(\mathrm{~N}_{\text {pass }}\right)$ & - \\
\hline 135 & 263007 & $\mathrm{SZ}$ \\
\hline 135 & 157551 & $\mathrm{SZ}$ \\
\hline 123.75 & $2000000\left(\mathrm{~N}_{\text {pass }}\right)$ & - \\
\hline
\end{tabular}

load cycles $[\mathrm{N}]$

differs from the expectations and the estimated values can have different reasons. It could be a hint, that the accuracy of stepwise load increase tests should be interpreted more conservatively for such Ti/Ti joints. In addition, batch- or tolerance-related variations in the roughness of the specimen as well as the accurate positioning in the servo-hydraulic testing machine can have an influence on the resulting fatigue behavior. Regarding the area of failure, differences were evident. While the FSW specimens failed comparatively in BM, HAZ and SZ, the failure of USE-FSW specimens occurred 
almost exclusively in the SZ, which indicates a higher reproducibility by means of ultrasound enhancement.

\section{Conclusions}

Similar joints of the industrial widely used titanium alloy Ti6Al4V could be successfully realized by using the conventional friction stir welding as well as the innovative hybrid joining process of ultrasound enhanced friction stir welding (USE-FSW). Afterwards, a comparative characterization regarding the microstructure and the quasi-static and cyclic mechanical properties was carried out. The following conclusions could be drawn:

(1) Both joining processes reached the diffusion controlled transformation zone of Ti6Al4V, whereas the USE-FSW process showed lower temperatures while welding as well as a more stable temperature development. This could be attributed to a change in the friction conditions by the softening of the materials due to the acousto-plastic effect.

(2) Regarding the microstructure of the two compared joints, remaining oxide layers were believed to be present in the FSW joint, whereas the USE-FSW joint had an improved intermixing and no visible oxide structures.

(3) The more detailed analysis of the resulting microstructure via scanning electron microscopy was generally in accordance with the literature and proved the presence of a minor proportion of globular primary $\alpha 1$ titanium.

(4) Ultimate tensile strength of the titanium joints could be increased by up to $16 \%$ when transmitting the additional power ultrasound into one of the metal sheets.

(5) The estimated fatigue strength by stepwise load increase tests showed a promising increase of about $20 \%$ for the USE-FSW process, which could not be confirmed by subsequent constant amplitude tests.

In general, the ultrasound enhanced friction stir welding process proved to be beneficial for the application on similar Ti6Al4V/Ti6Al4V joints.

Acknowledgements The investigations were supported by the Federal Ministry for Economic Affairs and Energy within the IGF Industrial Collective Research Program.

Funding Open Access funding enabled and organized by Projekt DEAL.

\section{Declarations}

Conflict of interest The authors declare that they have no conflict of interest.

Open Access This article is licensed under a Creative Commons Attribution 4.0 International License, which permits use, sharing, adaptation, distribution and reproduction in any medium or format, as long as you give appropriate credit to the original author(s) and the source, provide a link to the Creative Commons licence, and indicate if changes were made. The images or other third party material in this article are included in the article's Creative Commons licence, unless indicated otherwise in a credit line to the material. If material is not included in the article's Creative Commons licence and your intended use is not permitted by statutory regulation or exceeds the permitted use, you will need to obtain permission directly from the copyright holder. To view a copy of this licence, visit http://creativecommons.org/licenses/by/4.0/.

\section{References}

1. Goede M (2007) Karosserieleichtbau als Baustein einer CO2Reduzierungsstrategie, Aachen

2. Peters M (ed) (2010) Titan und Titanlegierungen, [3., völlig neu bearb. Aufl.], 3. Nachdr. Wiley-VCH, Weinheim

3. Malletschek A (2011) Einfluss von Titan auf den Entwurf von Unterwasserfahrzeugen, TUHH Universitätsbibliothek

4. Tomashchuk I, Grevey D, Sallamand P (2015) Dissimilar laser welding of AISI 316L stainless steel to Ti6-A14-6V alloy via pure vanadium interlayer. Mater Sci Eng A 622:37-45. https://doi.org/ 10.1016/j.msea.2014.10.084

5. Besharati Givi MK, Asadi P (2014) Advances in friction- stir welding. Woodhead Publishing In Mechanical Engineering. Woodhead Publishing, Cambridge, England, Waltham, Massachusetts, Oxford, England

6. Zhang Y, Sato YS, Kokawa $\mathrm{H}$ et al (2008) Microstructural characteristics and mechanical properties of Ti-6Al-4V friction stir welds. Mater Sci Eng A 485(1-2):448-455. https://doi.org/10. 1016/j.msea.2007.08.051

7. Liu HJ, Zhou L, Liu QW (2010) Microstructural characteristics and mechanical properties of friction stir welded joints of Ti-6Al4V titanium alloy. Mater Des 31(3):1650-1655. https://doi.org/10. 1016/j.matdes.2009.08.025

8. Edwards P, Ramulu M (2010) Identification of Process Parameters for Friction Stir Welding Ti-6Al-4V. Fatigue Fract Eng Mater Struct 132(3):173. https://doi.org/10.1115/1.4001302

9. Buffa G, Fratini L, Schneider M et al (2013) Effect of Process Parameters on the Joint Integrity in Friction Stir Welding of Ti-6Al-4V Lap Joints. KEM 554-557:1083-1090. https://doi. org/10.4028/www.scientific.net/KEM.554-557.1083

10. Wang J, Su J, Mishra RS et al (2014) Tool wear mechanisms in friction stir welding of Ti-6Al-4V alloy. Wear 321:25-32. https:// doi.org/10.1016/j.wear.2014.09.010

11. Buhl N (2014) Rührreibschweißen von Titanwerkstoffen und Analyse der Verbundeigenschaften. Zugl.: Kaiserslautern, Techn. Univ., Diss., 2014, Als Ms. gedr. Werkstoffkundliche Berichte, vol 32. Techn. Univ, Kaiserslautern

12. Pasta S, Reynolds AP (2008) Residual stress effects on fatigue crack growth in a Ti-6Al-4V friction stir weld. Fatigue Fract Eng Mater Struct 31(7):569-580. https://doi.org/10.1111/j.1460-2695. 2008.01258.x

13. Thomä M, Gester A, Wagner G et al (2019) Application of the hybrid process ultrasound enhanced friction stir welding on dissimilar aluminum/dual-phase steel and aluminum/magnesium 
joints. Materialwiss Werkstofftech 50(8):893-912. https://doi. org/10.1002/mawe.201900028

14. Straß B (2015) Ultraschallunterstütztes Rührreibschweißen von $\mathrm{Al} / \mathrm{Mg}$-Verbunden. $\mathrm{PhD}$, Technische Universität Kaiserslautern

15. Leonhardt S, Walter M (2016) Medizintechnische Systeme. Springer Berlin Heidelberg, Berlin, Heidelberg

16. Blaha F, Langenecker B (1955) Dehnung von Zink-Kristallen unter Ultraschalleinwirkung. Naturwissenschaften 42(20):556. https://doi.org/10.1007/BF00623773

17. Amini S, Amiri MR (2014) Study of ultrasonic vibrations' effect on friction stir welding. Int J Adv Manuf Technol 73(1-4):127135. https://doi.org/10.1007/s00170-014-5806-7

18. Ma Z, Jin Y, Ji S et al (2019) A general strategy for the reliable joining of $\mathrm{Al} / \mathrm{Ti}$ dissimilar alloys via ultrasonic assisted friction stir welding. J Mater Sci Technol 35(1):94-99. https://doi.org/10. 1016/j.jmst.2018.09.022

19. Padhy GK, Wu CS, Gao S et al (2016) Local microstructure evolution in Al 6061-T6 friction stir weld nugget enhanced by ultrasonic vibration. Mater Des 92:710-723. https://doi.org/10.1016/j. matdes.2015.12.094

20. Tarasov SY, Rubtsov VE, Fortuna SV et al (2017) Ultrasonicassisted aging in friction stir welding on $\mathrm{Al}-\mathrm{Cu}-\mathrm{Li}-\mathrm{Mg}$ aluminum alloy. Weld World 61(4):679-690. https://doi.org/10.1007/ s40194-017-0447-8

21. Thomä M, Gester A, Wagner G et al (2020) Analysis of the Oscillation Behavior of Hybrid Aluminum/Steel Joints Realized by Ultrasound Enhanced Friction Stir Welding. Metals 10(8):1079. https://doi.org/10.3390/met10081079

22. DIN 50100 (2016-12) Schwingfestigkeitsversuch - Durchführung und Auswertung von zyklischen Versuchen mit konstanter Lastamplitude für metallische Werkstoffproben und Bauteile. https:// doi.org/10.31030/2580844

23. Ebel-Wolf B, Walther F, Eifler D (2007) Cyclic deformation behaviour and lifetime calculation of the magnesium die-cast alloys AZ91D, MRI 153M and MRI 230D. Int J Mater Res 98(2):117-122. https://doi.org/10.3139/146.101443

24. Zhong YB, Wu CS, Padhy GK (2017) Effect of ultrasonic vibration on welding load, temperature and material flow in friction stir welding. J Mater Process Technol 239:273-283. https://doi.org/ 10.1016/j.jmatprotec.2016.08.025

25. Zhai M, Wu C, Su H (2020) Influence of tool tilt angle on heat transfer and material flow in friction stir welding. J Manuf Process 59(1):98-112. https://doi.org/10.1016/j.jmapro.2020.09.038

26. Wu T, Zhao F, Luo H et al (2019) Temperature Monitoring and Material Flow Characteristics of Friction Stir Welded 2A14-t6 Aerospace Aluminum Alloy. Materials (Basel) 12(20). https://doi. org/10.3390/ma12203387

27. Gangwar K, Mamidala R, Sanders D (2017) Friction Stir Welding of near $\alpha$ and $\alpha+\beta$ Titanium Alloys: Metallurgical and Mechanical Characterization. Metals 7(12):565. https://doi.org/10.3390/ met7120565

28. Sanders DG, Ramulu M, Klock-McCook EJ et al (2008) Characterization of Superplastically Formed Friction Stir Weld in Titanium 6AL-4V: Preliminary Results. J Mater Eng Perform 17(2):187-192. https://doi.org/10.1007/s11665-007-9186-0

29. Ahmadian P, Morakabati M (2020) The Effect of Lamellar and Globular $\alpha$-Phase on Mechanical Behavior of Strongly Textured Ti-6Al-4V alloy. Trans Indian Inst Met 73(5):1301-1309. https:// doi.org/10.1007/s12666-020-01957-1

Publisher's note Springer Nature remains neutral with regard to jurisdictional claims in published maps and institutional affiliations. 